\title{
A influência do território no comportamento do mercado de trabalho: notas sobre a experiência brasileira
}

Alberto de Oliveira. Universidade Federal do Rio de Janeiro (UfRJ), Rio de Janeiro, Brasil.

RESUMo | Os indicadores do mercado de trabalho brasileiro melhoraram na década de 2000. A taxa de desemprego diminuiu e o nível de formalização cresceu em praticamente todo o território brasileiro. No entanto, algumas heranças espaciais foram reforçadas e novos espaços foram desenvolvidos, o que significa que o perfil de subdesenvolvimento do mercado de trabalho brasileiro não se alterou. $\mathrm{O}$ trabalho apresenta uma discussão sobre a relação entre a especialização econômica espacial e do comportamento do mercado de trabalho. Suportado pela literatura e análise empírica, o documento mostra como o mercado de trabalho pode ser influenciado pelas características do território. Com base na experiência do Estado de São Paulo, o trabalho mostra evidências de que a especialização econômica espacial pode reduzir as oportunidades de emprego e os desempregados podem estar escondidos sob a sombra inatividade.

PALAVRas CHAVe | desenvolvimento regional e local, mercado de trabalho, governo local.

ABSTRACT | The Brazilian labor market indicators have improved in the decade of 2000 s. The unemployment rate declined and the formalization level rose in nearly all of the Brazilian territory. However, some spatial inheritances were reinforced and new spaces were developed, which means the underdeveloped profile of the Brazilian labor market did not change. The paper presents a discussion about the relation between the spatial economic specialization and the labor market behavior. Supported by literature and empirical analysis, the paper shows how territorial features can influence the labor market. Based on the São Paulo State experience the work shows evidence that the spatial economic specialization can reduce job opportunities and unemployed population could be hidden under the inactivity shadow.

KEYWORDS | regional and local development, labour market, local government.

Recibido el 9 de septiembre de 2014, aprobado el 1 de diciembre de 2015

E-mail: alberto@ippur.ufrj.br 


\section{Introduçáo}

A década de 2000 foi marcada por mudanças no desempenho da economia brasileira, gerando rebatimentos na configuração espacial e no mercado de trabalho. Os investimentos públicos e privados realizados reforçaram as heranças da formação econômica do país em alguns casos, enquanto, em outros, contribuíram para a abertura de novas frentes de expansão. Nesse contexto, chamou a atenção o declínio das taxas de desemprego, cujo patamar retornou ao nível semelhante àquele observado em período anterior a crise dos anos 1990 .

Ainda que o crescimento econômico tenha alcançado praticamente a totalidade do território brasileiro, cabe lembrar a forma diferenciada de inserção dos espaços na economia, gerando demandas igualmente diferenciadas para o mercado de trabalho. Em outros termos, este trabalho está baseado na convicção de que a configuração da atividade econômica tende a moldar as preferências de máo de obra das firmas, reforçando a idéia da existência de padróes espacializados de funcionamento do mercado de trabalho. Portanto, o objetivo desse artigo é apresentar elementos que contribuam para elucidar a influência do território no comportamento do mercado de trabalho.

Para alcançar os objetivos propostos, o estudo foi organizado em quatro sessôes, além dessa introdução. A primeira apresentou breves traços sobre a política macroeconômica adotada nos anos 2000 e seus efeitos sobre o mercado de trabalho. Em seguida, discutiram-se os referenciais teóricos que justificariam a influência do território sobre o comportamento do mercado de trabalho. A terceira sessão examina o mercado de trabalho do Estado de São Paulo, buscando oferecer suporte empírico às conclusôes extraídas no exame da literatura. Algumas considerações são apontadas ao final do trabalho.

\section{Crescimento econômico e mercado de trabalho no Brasil: a década virtuosa}

O crescimento econômico e a melhoria do mercado de trabalho no Brasil, na década de 2000, resultaram de ampla combinação de fatores. O desempenho favorável das exportaçôes brasileiras, notadamente de commodities, foi acompanhado de política macroeconômica pró-cíclica que resultou no aumento dos negócios no mercado doméstico. Ao lado disso, a redução dos juros no mercado internacional, o aumento das reservas internacionais e a trajetória positiva da relação dívida pública/ PIB criaram as condiçóes suficientes para a redução das taxas de juros internas, incrementando os investimentos.

A retomada da economia incentivou o crescimento da ocupação em geral e do emprego formalizado, em particular. A melhoria do mercado de trabalho e a estabilidade da ocupação, juntamente com o aumento da oferta de crédito, foram decisivas para o aumento do consumo no mercado doméstico. Esse novo contexto modificou as estratégias das empresas. As grandes redes varejistas tiveram desempenho excepcional, nos anos 2000, enquanto os segmentos que tradicionalmente não atendem às camadas mais pobres da população, como os bancos, adotaram estratégias agressivas para ingressar nesse mercado. A implantação de programas 
habitacionais, o redirecionamento do foco das empresas e o aumento do crédito intensificaram os negócios no mercado imobiliário, reforçando o investimento na Construção Civil e gerando efeitos positivos sobre a ocupação, realimentando a trajetória ascendente da economia.

Entre 2000 e 2010, foram criados mais de 20 milhóes de novos postos de trabalho no país, quase metade deles na Região Sudeste. Nas regiōes Norte e Nordeste, áreas historicamente marcadas por crônica vulnerabilidade social, mais de 6 milhóes de ocupaçóes foram criadas no período. O crescimento intenso da ocupação na Região Centro Oeste foi em grande medida explicado pela exportação de commodities. E na Região Sul, onde figuram os melhores indicadores sociais do país, o crescimento dos postos de trabalho acompanhou a média nacional (tabela 1).

TABELA I | Evolução da ocupaçáo nas regióes brasileiras entre 2000 e 2010

\begin{tabular}{|c|c|c|c|c|}
\hline \multirow{2}{*}{$\begin{array}{c}\text { REGIÓES } \\
\text { BRASILEIRAS }\end{array}$} & \multirow[b]{2}{*}{2000} & \multirow[b]{2}{*}{2010} & \multicolumn{2}{|c|}{ VARIAÇÃO 2000-20IO } \\
\hline & & & $\begin{array}{c}\text { NÚMEROS } \\
\text { ABSOLUTOS }\end{array}$ & $\begin{array}{c}\text { TAXA } \\
\text { GEOMÉTRICA }\end{array}$ \\
\hline Brasil & 65.629 .892 & 86.353 .839 & 20.723 .947 & 2,8 \\
\hline Norte & 4.371 .348 & 6.262 .341 & 1.890 .993 & 3,7 \\
\hline Nordeste & 16.384 .648 & 20.854 .301 & 4.469 .653 & 2,4 \\
\hline Sudeste & 29.088 .409 & 38.111 .800 & 9.023 .391 & 2,7 \\
\hline Sul & 10.996 .193 & 14.249 .772 & 3.253 .579 & 2,6 \\
\hline Centro-Oeste & 4.789 .295 & 6.875 .625 & 2.086 .330 & 3,7 \\
\hline
\end{tabular}

FONTE IBGE/CENSO DEMOGRÁFICO

Ainda que o crescimento econômico registrado na década de 2000 tenha alcançado parcela expressiva do território nacional, tal movimento foi insuficiente para modificar as situaçóes de desigualdades historicamente construídas no Brasil. Em 2010, as taxas de desemprego das regióes Norte e Nordeste estavam situadas em patamar superior ao observado nas demais regiōes brasileiras. Além disso, enquanto no Sudeste a taxa de desemprego diminuiu quase 9 pontos percentuais (de $16,4 \%$ para $7,5 \%$ ), no Nordeste o mesmo indicador declinou 6 pontos percentuais (de 15,9\% para 9,7\%), colocando o Nordeste no topo do desemprego do país, em 2010 (tabela 2).

TABEla 2 Evoluçáo da taxa de desemprego total no Brasil segundo regióes entre 2000 e 2010

\begin{tabular}{|l|c|c|}
\hline \multicolumn{1}{|c|}{ REGIÓES } & 2000 & 20IO \\
\hline Brasil & 15,3 & 7,6 \\
\hline Norte & 14,8 & 8,7 \\
\hline Nordeste & 15,9 & 9,7 \\
\hline Sudeste & 16,4 & 7,5 \\
\hline Sul & 12,0 & 4,7 \\
\hline Centro-Oeste & 13,7 & 6,6 \\
\hline
\end{tabular}

FONTE IBGE/CENSO DEMOGRÁFICO 
É interessante observar que a taxa de desemprego varia de acordo com o tamanho da população. O desemprego tende a ser mais elevado à medida que crescem os contingentes populacionais. Em 2010, a taxa média de desemprego dos municípios com até 100.000 habitantes era de 6,7\%, enquanto nas metrópoles com mais de 1 milhão de habitantes a taxa de desemprego era de $8,2 \%$. As cidades com população intermediária registraram níveis de desemprego semelhantes àqueles observados nas grandes cidades (tabela 3).

Outro elemento importante que diferencia as grandes cidades dos pequenos municípios é o grau de inserção da população no mercado de trabalho, particularmente entre as mulheres. A tabela 3 mostra que a taxa de participação total das cidades com até 100.000 habitantes era de 55,2\%, enquanto para as metrópoles com mais de 1 milhão de habitantes esse indicador era de 60,5\%. Essa diferença é explicada pela inserção das mulheres no mercado de trabalho, enquanto nas pequenas cidades a taxa de participaçáo feminina era de $44,0 \%$, nos grandes centros esse percentual alcançava 53,5\%. Também existem diferenças na participação dos jovens entre os núcleos urbanos, contudo, informações mais detalhadas não foram colhidas para este trabalho. Mesmo entre a população masculina a taxa de participação apresenta variaçóes importantes: $66,1 \%$ nas pequenas cidades e 68,5\% nas metrópoles.

TABela 3 | Taxa de participaçáo e taxa de desemprego segundo sexo e tamanho do município. Estados brasileiros selecionados (2010)

\begin{tabular}{|l|c|c|c|c|c|}
\hline \multirow{2}{*}{ TAMANHO DO MUNICÍPIO } & \multirow{2}{*}{$\begin{array}{c}\text { NÚMERO DE } \\
\text { MUNICÍPIOS }\end{array}$} & \multicolumn{2}{|c|}{ TAXA DE PARTICIPAÇÃo } & \multirow{2}{*}{ TAXA DE } \\
\cline { 3 - 5 } & TOTAL & MASCULINA & FEMININA & DESEMPREGO \\
\hline Até 100.000 hab. & 3.158 & 55,2 & 66,1 & 44,0 & 6,7 \\
\hline De 100.001 a 1.000.000 hab & 177 & 59,1 & 68,5 & 50,2 & 8,3 \\
\hline Mais de 1.000.000 hab. & 9 & 60,5 & 68,5 & 53,5 & 8,2 \\
\hline
\end{tabular}

FONTE CENSO DEMOGRÁFICO 2OIO. A AMOSTRA INCLUI OS MUNiCípios DOS ESTADOS DO RIO DE

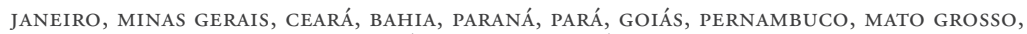
MATO GROSSO DO SUL E SÃo PAULO (EXCLUÍDA A RMSP)

O comportamento da inserção dos indivíduos no mercado de trabalho influencia, decisivamente, o nível da taxa de desemprego. Pequenas variaçóes positivas ou negativas na taxa de participação geram mudanças importantes na taxa de desemprego, uma vez que a taxa de desemprego varia de acordo com o tamanho da População Economicamente Ativa (PEA). Os fatores que podem influenciar o comportamento da taxa de participação podem ser divididos, grosso modo, em dois grandes grupos: os ligados aos indivíduos e os ligados ao território.

Dentre os fatores individuais que afetam o tamanho da PEA destaca-se o aumento da participação feminina no mercado de trabalho. Transformaçóes culturais no papel da mulher na sociedade explicam parte do crescimento da PEA feminina, fenômeno que não se restringe ao caso brasileiro. No entanto, é preciso considerar que o aumento das taxas de desemprego nos anos 1990, comprometendo a renda familiar, atuou como um forte incentivo para o ingresso das mulheres no mercado 
de trabalho (Leone, 1999). Em muitos casos, a inserção feminina no mercado de trabalho brasileiro ocorreu de forma precarizada, como é o caso do emprego doméstico informal. Do ponto de vista do território, a composição da população segundo gênero e faixa etária podem alterar os resultados da taxa de participaçáo total. Por fim, há diferenças que são oriundas do viés estatístico derivado da implantação de programas assistenciais. O caso típico é o do beneficiário do Programa Bolsa Família que omite a sua condição de ocupado (reduzindo a renda familiar) para preservar o recebimento do benefício.

Ainda que variaçóes no tamanho da PEA alterem a taxa de desemprego, não restam dúvidas que a criação de novos postos de trabalho ocorre apenas como consequência do crescimento econômico. O aumento nos negócios cria as condiçôes necessárias que acionarão o investimento, levando ao crescimento do emprego. Portanto, as questóes-chave dessa investigação são: (i) constatado o crescimento econômico, quais são as particularidades do território capazes de influenciar a configuração do mercado de trabalho? (ii) Existem pessoas que não conseguem obter um posto de trabalho, a despeito do crescimento da economia? Por quê?

\section{O território interfere no mercado de trabalho? Como?}

A teoria neoclássica estabelece que o trabalho, a semelhança das demais mercadorias, é regulado pelas forças do mercado. Do lado da oferta, os fluxos de mão de obra seriam guiados pelo desejo dos indivíduos de maximizar os salários. A intensidade e a direção das migraçóes estariam relacionadas com a pobreza das áreas de origem e as oportunidades do destino, enquanto os obstáculos para o deslocamento atuariam como freios para as migraçôes (Lee, 1980; Ravenstein, 1980). O estabelecimento de salários mínimos nas áreas urbanas reforçaria o diferencial de rendimentos entre o campo e a cidade, reforçando os fluxos migratórios (Harris \& Todaro, 1980). No entanto, os deslocamentos campo-cidade não pressionariam os salários no campo, nem comprometeria a produção de alimentos porque o trabalho movido para as cidades seriam compensados pelo aumento da produtividade no campo (Ranis \& Fei, 1964).

Do lado da demanda, o crescimento das oportunidades de trabalho seria inversamente proporcional à expansão dos salários. Os empresários estariam dispostos a contratar mão de obra adicional até o limite quando "o salário for igual ao produto marginal do trabalho" (Keynes, 1983). Para os neoclássicos, o desemprego seria explicado por dois motivos: friccionais e voluntários. O primeiro está relacionado ao processo de ajustamento temporal entre oferta e demanda de trabalho, decorrente da adaptação da mão de obra frente às novas habilidades requeridas pelo mercado em razão dos avanços nas técnicas produtivas. Já o desemprego voluntário estaria relacionado à rigidez dos salários produzida pela a regulação do trabalho e pelas pressôes exercidas pelos sindicados, entre outros motivos. Todos esses elementos impediriam que os salários se movessem de acordo com a produtividade marginal do trabalho, impedindo a maximização do mercado de trabalho.

Os teóricos não alinhados com a ortodoxia econômica entendem que o processo de formação econômica, que define a forma de inserção dos países no mercado internacional, determina os contornos da estrutura produtiva e do mercado de trabalho. 
Por este raciocínio, a crônica heterogeneidade do mercado de trabalho brasileiro seria resultado do caráter retardatário da inserção do país no mercado internacional, pois, a transição da escravidão para o trabalho livre deixou como legado expressivo contingente de mão de obra que foi absorvido pelos colchóes amortecedores das economias de subsistência, sobretudo no Nordeste do país.

Dedecca (2005) explicou que a Lei de Terras de 1850, que sancionou a rigidez da estrutura fundiária no Brasil, subordinou a mão de obra livre ao trabalho no latifúndio. A expansão da fronteira agrícola pela população livre ocorreu de forma precária e sem o respaldo do Estado, o que tornava frequente a expulsão desses trabalhadores pelos latifundiários. Em 1879, a promulgação da legislação, que regulou o trabalho em regime de colonato e de parceria, estabeleceu o caráter privado da relação de trabalho e garantiu ao proprietário da terra a autonomia para definir as regras do contrato de trabalho. Finalmente, a política de imigraçáo trouxe milhares de trabalhadores estrangeiros para São Paulo em detrimento do contingente populacional imobilizado nos latifúndios nordestinos. Todos esses elementos contribuíram para a constituição de um mercado de trabalho com fortes traços de desigualdade, no qual excedente de mão de obra em situação de desemprego convive ao lado de demandas não atendidas de mão de obra qualificada.

A heterogeneidade do mercado de trabalho não é um fenômeno exclusivamente observado nos países com inserção retardatária. A redução do ritmo do crescimento econômico nos países centrais, sobretudo a partir da década de 1970, vem corroendo as relaçóes de emprego e gerando conseqüências negativas sobre a estabilidade da ocupaçáo e os sistemas públicos de amparo ao trabalhador. Oliveira e Carvalho (2008) investigaram o comportamento do trabalho temporário para avaliar o processo de precarizaçáo do mercado de trabalho europeu e concluíram que efeitos negativos sobre o mercado de trabalho podem ser encontrados em toda a Europa Ocidental, ainda que de forma diferenciada entre os países. Tal movimento seria decorrente de mudanças estruturais que vêm redefinindo negativamente as relaçôes de emprego, seja por meio da liberalização das demissôes individuais e coletivas, seja pela expansão do trabalho temporário. As autoras ressaltaram que o aumento do trabalho temporário não é consequência da escolha dos indivíduos, mas resultado da dificuldade de obtençáo de um posto de trabalho.

Todos esses elementos apontam para a necessidade de interpretar o funcionamento do mercado de trabalho a partir da desigualdade, tornando oportuno incorporar os princípios da teoria da segmentação do mercado de trabalho. Para os adeptos da segmentaçáo, o mercado de trabalho seria formado pela somatória de múltiplos mercados que atuariam simultaneamente, porém, com baixa permeabilidade entre si. A teoria da segmentação, também conhecida como teoria do mercado dual, estabelece que o mercado de trabalho estaria dividido em dois mercados: o primário e o secundário. O mercado primário seria marcado pelos seguintes traços: estabilidade do posto de trabalho, elevada remuneração, alta produtividade, progresso técnico e mecanismos explícitos de progressão profissional. Já os trabalhadores do mercado secundário estariam sujeitos à baixa remuneraçáo, menor produtividade, elevada rotatividade no emprego, estagnação tecnológica e desemprego crônico (Lima, 1980). 
Lima (1980) classificou os autores vinculados à teoria da segmentação em três grupos: o primeiro, liderado Doeringer e Piore, atribui as causas da segmentação às características pessoais dos trabalhadores, ou seja, estudam o lado da oferta. $\mathrm{O}$ segundo grupo, formado por Bluestone, Harrison e Victorisz, situa as causas da segmentação do lado da demanda, enquanto o último grupo, representado por Reich, Marglin e Gintis, entre outros, entende que a dinâmica capitalista explicaria a segmentação do mercado de trabalho.

Os autores que analisam a segmentação pelo lado da oferta defendem que as empresas atuam em mercados diferenciados. Empresas com demanda estável tendem a reter empregados ligados ao mercado primário de trabalho. Já as empresas que atuam sob forte instabilidade apresentam elevada rotatividade de mão de obra e, consequentemente, buscam seus empregados no mercado secundário. Os trabalhadores, por sua vez, incorporariam padrōes de comportamento relacionados ao mercado de trabalho no qual atuam (primário e secundário). Por isso, "trabalhando em condiçôes de emprego intermitentes e erráticas, o trabalhador tende a perder hábitos de regularidade e pontualidade, atrasos e faltas são aceitos com naturalidade pelos empregadores do mercado secundário, que assim incentivam a participação instável dos trabalhadores neste mercado" (Lima, 1980, p. 237). Por isso, a alocação de máo de obra nos diferentes mercados seria condicionada ao comportamento dos próprios trabalhadores.

Os economistas que explicam a segmentação pelo lado da demanda propóem que as características das empresas definiriam o perfil da mão de obra. Os oligopólios, que são intensivos em capital e que atuam em mercados relativamente protegidos, captariam sua força de trabalho no mercado de trabalho primário. Já as pequenas empresas, que atuam em mercados altamente competitivos e que se distinguem pela baixa produtividade e pela intensidade do uso de máo de obra, tenderiam a buscar seus trabalhadores no mercado de trabalho secundário. Portanto, "a segmentação do mercado de trabalho, a mobilidade ocupacional e os níveis de salários estáo direta e indiretamente ligados a fatores institucionais que definem o poder de mercado de diferentes indústrias" (Lima, 1980, p. 241).

Finamente, o terceiro grupo de economistas defende que as forças políticas e econômicas intrínsecas ao capitalismo seriam as responsáveis pela formação de mercados de trabalho segmentados. Para estes autores, a segmentaçáo do mercado de trabalho teria sido construída na fase do capitalismo monopolista como estratégia deliberada de desmobilização dos trabalhadores. Nos primórdios do capitalismo, a composição da força de trabalho seria relativamente mais homogênea, gerando maior poder de barganha sobre o capital. Desta forma, a segmentação do mercado de trabalho estaria inserida numa estratégia do tipo dividir para governar.

Monopoly capitalist corporations devised deliberate strategies to solve the contradictions between the increased proletarianization of the work force and the growth and consolidation of concentrated corporate power. The central thrust of the new strategies was to break down the increasingly unified worker interests that grew out of the proletarianization of work and the concentration of workers in urban areas. (Reich, Gordon $\&$ Edwards, 1973, p. 361) 
Embora a teoria da segmentação ofereça pistas para o entendimento do mercado de trabalho brasileiro, é preciso levar em conta o contexto histórico no qual esses trabalhos foram produzidos e, principalmente, o traço determinista presente nestas abordagens. Por isso, ainda que náo seja possível transpor diretamente os fatores explicativos expostos nessa literatura para as circunstâncias brasileiras, é possível admitir que as variaçóes na atividade econômica afetam, de forma diferenciada, os distintos segmentos do mercado de trabalho. Na maioria dos casos, os trabalhadores qualificados (que integram o mercado primário) estão mais protegidos nos momentos de declínio e são mais competitivos na retomada da economia, exatamente porque foram poupados na crise. No sentido oposto, os trabalhadores do mercado secundário se movem do emprego para o desemprego (e vice-versa) seguindo as flutuaçóes da economia. A instabilidade do posto de trabalho e a elevada rotatividade, que são inerentes ao mercado secundário, reforçam a vulnerabilidade dos trabalhadores.

A investigação sobre os efeitos das variaçóes da atividade econômica sobre os segmentos do mercado trabalho traz consigo a discussão sobre o comportamento da PEA, pois as flutuaçóes da ocupação são usualmente acompanhadas por movimentos de entrada e saída de pessoas no mercado de trabalho. Em outras palavras, as trajetórias no mercado de trabalho não são unidirecionais passando da inatividade para o desemprego e, deste, para a ocupação. Ao contrário, o mercado de trabalho é caracterizado pela multiplicidade de trajetórias realizadas pelos indivíduos. Os estudos sobre o comportamento da PEA vêm atraindo a atenção dos pesquisadores, desde os anos 1930, em resposta a observação de flutuaçóes no mercado de trabalho associadas aos movimentos da economia. A literatura econômica identifica duas motivaçôes que explicariam os fluxos da PEA, que foram batizadas de: (i) teoria do trabalhador adicional e (ii) teoria do trabalhador desencorajado/desalentado (Cohen, Lerman \& Rea, 1971).

A teoria do trabalhador adicional, partindo da análise da renda familiar, estabelece que os membros da família aumentam a participação no mercado de trabalho em resposta à queda no orçamento familiar, em geral, como resultado do desemprego do chefe da família ou de outro membro cujo salário represente fatia importante do rendimento familiar. Assim, a teoria do trabalhador adicional, como sugere o termo, explicaria movimento de expansão da taxa de participação, ou seja, da entrada de pessoas na PEA.

Já a teoria do desalento, ou teoria do trabalhador desencorajado, busca explicaçóes para os movimentos de saída da PEA. Em breves traços, o declínio da atividade econômica, especialmente nos períodos de recessão, reduz a oferta de postos de trabalho, conseqüentemente, aumentando a disputa pelas vagas disponíveis e desencorajando o ingresso no mercado de trabalho.

Em períodos de declínio da atividade econômica, a combinação destes dois movimentos ajudaria a explicar o tamanho da PEA. Em termos gerais, a análise dos efeitos descritos na teoria do trabalhador adicional e na do desalento seriam simples aplicaçóes da teoria tradicional de oferta de trabalho no contexto familiar (Gonzaga e Reis, 2005). Os estudos pioneiros sobre o assunto, realizados no imediato pósguerra, tinham a expectativa de compreender o comportamento dos fluxos da PEA, especialmente entre mulheres e jovens. 
Mulheres, jovens, idosos e imigrantes são os grupos que apresentam flutuaçóes mais intensas na PEA. Tais populaçóes estão relativamente menos amparadas pelos programas previdenciários e de seguro desemprego. Por isso, tendem a integrarse no mercado de trabalho secundário. Além do perfil individual, as condiçóes socioeconômicas dos trabalhadores também influenciariam a entrada no mercado de trabalho. Mooney (1967) mostrou que a taxa de participação de pessoas pobres e mulheres negras seria mais elevada em comparação a das pessoas não-pobres e mulheres brancas casadas.

Incorporando o território como uma das variáveis que poderiam afetar o comportamento do mercado de trabalho, não seria possível admitir que as características específicas da economia local ou regional pudessem interferir na disposição dos trabalhadores em ingressar (ou não) no mercado de trabalho, afetando, com isso, a taxa de desemprego? Esta, portanto, seria a chave que ligaria o território ao comportamento do mercado de trabalho. Vinculaçôes diretas entre território e mercado de trabalho são encontradas nos estudos inspirados no conceito spatial mismatch.

A teoria spatial mismatch toma como eixo a problemática das distâncias geográficas e das fricçốes que contribuiriam para separar os bolsóes de mão de obra dos sítios onde estão localizados os postos de trabalho. Nos anos 1960, Kain (1968) analisou os efeitos da segregação urbana da população negra em Chicago e Detroit, concluindo que os custos de transporte e as limitaçóes de acesso à informação reduziriam as chances de obtenção de emprego para a população de baixa renda, aumentando o desemprego e/ou desestimulando a busca por emprego entre as pessoas residentes naquelas cidades americanas.

There are several reasons why housing market segregation may affect the distribution and level of Negro employment. The most obvious are: (1) the distance to and difficulty of reaching certain jobs from Negro residence areas may impose costs on Negroes high enough to discourage them from seeking employment there. (2) Negroes may have less information about and less opportunity to learn about jobs distant from their place of residence or those of their friends. (3) Employers located outside the ghetto may discriminate against Negroes out of real or imagined fears of retaliation from white customers for bringing Negroes into all-white residential areas, or they may feel little pressure not to discriminate. (4) Similarly, employers in or near the ghetto may discriminate in favor of Negroes. (Kain, 1968, p. 179)

A despeito dos avanços trazidos pelo spatial mismatch, o foco na questão da segregaçáo racial e a introduçáo do espaço na forma de distâncias e de custos parecem insuficientes para incorporar a complexidade da influência do território sobre o comportamento da economia e, particularmente, sobre o mercado de trabalho. A discussão de custos e distâncias remete ao traço típico das teorias neoclássicas de localização industrial, no qual o território ocupa posição passiva de palco frente aos acontecimentos que se desenrolam por força dos mecanismos de mercado.

A hipótese desse trabalho é que os recortes geográficos são dotados de estruturas econômicas particulares, que podem ser (ou não) especializadas em determinadas atividades ou setores. Isso significa que a especialização econômica pode restringir a variedade do perfil da mão de obra, diminuindo as chances de inserção no mercado 
de trabalho para os trabalhadores cujo perfil não atende as necessidades do mercado. No sentido oposto, territórios caracterizados por um leque diversificado de atividades econômicas podem oferecer postos de trabalho que podem ser ocupados por indivíduos com diferentes traços pessoais, como escolaridade, sexo, faixa etária, etc. Em suma, espaços dotados de mercados diversificados tenderiam a oferecer mais oportunidades de trabalho quando comparados a economias especializadas. A fim de avançar na investigação, foram tomadas informaçóes do mercado de trabalho dos municípios paulistas, cujos resultados são apresentados a seguir.

\section{Diversidade econômica e mercado de trabalho no Estado de Sáo Paulo}

Nesse trabalho, o número de divisóes econômicas com pelo menos 01 empregado será utilizado como proxy para representar a idéia de diversidade econômica dos territórios. As divisôes econômicas seguem o estabelecido na Classificação Nacional de Atividades Econômicas (CNAE) e a fonte de dados primária é a Relação Anual de Informaçóes Sociais (RAIs), disponibilizada pelo Ministério do Trabalho e Emprego (MTE). Portanto, quanto mais elevado for o número de divisôes econômicas diferentes presentes no território, mais diversificada será considerada a economia deste território. A diversidade econômica será comparada com a taxa de desemprego e a taxa de participação total e por sexo dos respectivos recortes geográficos, de forma a identificar as relaçôes entre a diversidade econômica e o comportamento do mercado de trabalho. As informaçóes sobre a taxa de desemprego e a taxa de participação foram extraídas do Censo demográfico.

Os municípios paulistas foram divididos em quatro grupos a partir da análise de cluster, que posteriormente foram ajustados de acordo com a proximidade geográfica da Região Metropolitana de Sáo Paulo (RMSP). A idéia-chave é que os territórios no entorno da RMSP tendem a apresentar diversidade econômica e mercados de trabalho semelhantes, enquanto territórios localizados em outros quadrantes do Estado de São Paulo tenderiam a apresentar estruturas econômicas diferentes da observada na RMSP (tabela 4).

TABEla 4 Grupos de municípios de acordo com a diversidade econômica

\begin{tabular}{|l|l|}
\hline \multicolumn{1}{|c|}{ AGRUPAMENTOS } & \multicolumn{1}{|c|}{ COMPOSIÇÃo } \\
\hline $\begin{array}{l}\text { Grupo 1 - Municípios com menor diversidade } \\
\text { econômica, localizados fora do entorno da RMSP }\end{array}$ & Municípios não classificados nos grupos anteriores \\
\hline $\begin{array}{l}\text { Grupo 2 - Municípios com maior diversidade } \\
\text { econômica, localizados fora do entorno da RMSP }\end{array}$ & $\begin{array}{l}\text { Municípios que integram as regiôes de governo de } \\
\text { São José do Rio Preto e de Ribeirão Preto }\end{array}$ \\
\hline $\begin{array}{l}\text { Grupo 3 - Municípios com maior diversidade } \\
\text { econômica, localizados no entorno da RMSP }\end{array}$ & $\begin{array}{l}\text { Municípios que integram as regiôes de governo } \\
\text { de Campinas, São José dos Campos, Sorocaba, } \\
\text { Santos, Jundiaí e Piracicaba }\end{array}$ \\
\hline $\begin{array}{l}\text { Grupo 4 - Municípios da RMSP independentemente } \\
\text { da diversidade econômica }\end{array}$ & Municípios que integram a RMSP \\
\hline
\end{tabular}


A tabela 5 mostra que a inserção das pessoas no mercado de trabalho aumenta proporcionalmente ao nível de diversidade econômica do território. O Grupo 4 (RMSP), que possui 43 diferentes divisóes econômicas, apresenta taxa de participação de $59,2 \%$. Enquanto os municípios do Grupo 1, caracterizados por baixa diversidade econômica e localizados fora do entorno da RMSP, possuem, em média, 22 divisóes econômicas e sua taxa de participação é de $56,1 \%$. A tabela 5 também mostra que a diferença nas taxas totais de participação dos municípios é fortemente influenciada pela participação das mulheres no mercado de trabalho. Enquanto a taxa de participação das mulheres residentes nos municípios do Grupo 1 é de 40,4\%, a taxa de participação feminina do Grupo 4 é de $46,8 \%$. As taxas de participação masculina não apresentam diferenças relevantes entre os grupos de municípios: $71,2 \%$ para o Grupo 1 e $72,8 \%$ para o grupo 4 .

A discrepância no comportamento da taxa de participação entre homens e mulheres está relacionada a fatores econômicos, espaciais e culturais. Do ponto de vista cultural, as obrigaçóes da maternidade tendem a afastar as mulheres do mercado de trabalho, enquanto o usual papel de provedor da família reforça a inserção masculina. Esse traço cultural tende a ser reforçado quando se considera o diferencial de salários entre homens e mulheres, o que torna mais vantajoso para a família sacrificar a ocupação da mulher em favor da atenção dos filhos.

TABEla 5 | Taxas de participação em relação ao nível de diversidade econômica. Municípios do estado de Sáo Paulo - 2000/2002 (*)

\begin{tabular}{|c|c|c|c|c|}
\hline \multirow{2}{*}{ AGRUPAMENTOS DE MUNICÍPIOS } & \multirow{2}{*}{\begin{tabular}{|c|} 
MÉDIA DE \\
DIVISÓESS \\
ECONÔMICAS
\end{tabular}} & \multicolumn{3}{|c|}{ TAXAS DE PARTICIPAÇÃO (MÉDIA) } \\
\hline & & TOTAL & MASCULINA & FEMININA \\
\hline $\begin{array}{l}\text { Grupo } 1 \text { - Municípios com menor diversidade } \\
\text { econômica, localizados fora do entorno da RMSP }\end{array}$ & 22 & $56,1 \%$ & $71,2 \%$ & $40,4 \%$ \\
\hline $\begin{array}{l}\text { Grupo } 2 \text { - Municípios com maior diversidade } \\
\text { econômica, localizados fora do entorno da RMSP }\end{array}$ & 24 & $58,2 \%$ & $73,4 \%$ & $42,7 \%$ \\
\hline $\begin{array}{l}\text { Grupo } 3 \text { - Municípios com maior diversidade } \\
\text { econômica, localizados no entorno da RMSP }\end{array}$ & 37 & $59,3 \%$ & $72,4 \%$ & $46,0 \%$ \\
\hline $\begin{array}{l}\text { Grupo } 4 \text { - Municípios da RMSP } \\
\text { (independentemente da diversidade econômica) }\end{array}$ & 43 & $59,2 \%$ & $71,8 \%$ & $46,8 \%$ \\
\hline
\end{tabular}

FONTES RAIS E CENSO DEMOGRÁFICO

$\left.{ }^{*}\right)$ ANO-BASE: 2000 PARA OS DADOS DO CENSO E 2002 PARA OS DA RAIS

No que tange ao território, taxas mais elevadas de participação feminina na RMSP podem estar associadas ao tamanho e a diversidade do setor Terciário, especialmente as atividades comerciais, nas quais existem mais oportunidades de ocupação para as mulheres. Em outras palavras, a baixa diversificaçáo de atividades pode estar servindo de barreira a entrada as mulheres no mercado de trabalho dos pequenos centros urbanos.

Para reforçar os argumentos propostos, realizou-se a análise de variância para comprovar a existência diferenças estatisticamente significativas nas taxas de participação (total, masculina e feminina) nos recortes geográficos estabelecidos nessa 
pesquisa. A análise de variância (com correção de Brown Forsythe) foi realizada tendo em vista a sua melhor adequação para os casos que apresentam heterocedasticidade (ou seja, quando a variância não é constante entre grupos) conforme foi observado (por meio do teste de Levene) para os grupos de municípios investigados. Assim, foi possível constatar que as médias de todas as taxas de participação apresentam diferenças estatisticamente significativas ( $p$-value $<0,001$ ) entre os grupos de municípios selecionados (tabela 6 ). A realizaçáo de comparaçóes múltiplas de $C$ de Dunnet permite especificar os grupos nos quais essas diferenças são estatisticamente significativas, como segue:

- Para a taxa de participação total: existem diferenças estatisticamente significativas entre o grupo 1 (municípios com menor diversidade econômica localizados fora do entorno da RMSP), cuja taxa de participação é 56,1\% e os demais grupos de cidades, que registraram taxas de participação total entre 58,2\% e 59,2\%;

- Para a taxa de participação masculina: essa taxa não apresenta diferenças significativas entre os grupos de municípios 1 e 4, cujas taxas de participação são, respectivamente, $71,2 \%$ e $71,8 \%$. Diferenças significativas foram registradas entre o grupo 2 (taxa de participação de 73,4\%) e os demais agrupamentos;

- Para a taxa de participação feminina: existem diferenças entre todos os agrupamentos, exceto entre os grupos 3 e 4, cujas taxas de participação são 46,8\% e $46,0 \%$, respectivamente. A ausência de diferença estatística entre os grupos 3 e 4 reforça a semelhança desses mercados de trabalho que apresentam proximidade geográfica.

Tabela 6 | Distribuição das Taxas de Participação Femininas segundo Grupos de Municípios segundo Diversidade Econômica - Estado de São Paulo - 2000/2002 (*)

\begin{tabular}{|c|c|c|c|c|c|c|}
\hline \multirow{2}{*}{$\begin{array}{c}\text { TAXA DE } \\
\text { PARTICI- } \\
\text { PAÇÃO }\end{array}$} & \multirow[t]{2}{*}{ GRUPOS DE MUNICÍPIOS } & \multirow{2}{*}{$\begin{array}{c}\text { NÚMERO DE } \\
\text { MUNICÍPIOS } \\
\text { DE CADA } \\
\text { GRUPO }\end{array}$} & \multirow{2}{*}{$\begin{array}{c}\text { MÉDIA DAS } \\
\text { TAXAS DE } \\
\text { PARTICI- } \\
\text { PAÇÃO }\end{array}$} & \multirow{2}{*}{$\begin{array}{l}\text { DESVIO } \\
\text { PADRÃo }\end{array}$} & \multicolumn{2}{|c|}{$\begin{array}{c}\text { INTERVALO DE } \\
\text { CONFIANÇA }(95 \%) \\
\text { LIMITES }\end{array}$} \\
\hline & & & & & INFERIOR & SUPERIOR \\
\hline \multirow{6}{*}{ Total } & $\begin{array}{l}\text { Grupo } 1 \text { - Municípios com } \\
\text { menor diversidade econômica, } \\
\text { localizados fora do entorno da } \\
\text { RMSP }\end{array}$ & 465 & 56,1 & 4,3 & 55,7 & 56,5 \\
\hline & $\begin{array}{l}\text { Grupo } 2 \text { - Municípios com maior } \\
\text { diversidade econômica, localizados } \\
\text { fora do entorno da RMSP }\end{array}$ & 56 & 58,2 & 3,0 & 57,4 & 59,0 \\
\hline & $\begin{array}{l}\text { Grupo } 3 \text { - Municípios com maior } \\
\text { diversidade econômica, localizados } \\
\text { no entorno da RMSP }\end{array}$ & 85 & 59,3 & 3,1 & 58,6 & 59,9 \\
\hline & $\begin{array}{l}\text { Grupo } 4 \text { - Municípios da RMSP } \\
\text { (independentemente da } \\
\text { diversidade econômica) }\end{array}$ & 39 & 59,2 & 2,1 & 58,5 & 59,8 \\
\hline & Total dos municípios & 645 & 56,9 & 4,2 & 56,6 & 57,2 \\
\hline & \multicolumn{6}{|c|}{ Teste de Brown Forsythe apresentou $p$-value $=\mathbf{0 , 0 0 0}$} \\
\hline
\end{tabular}


(continuação)

\begin{tabular}{|c|c|c|c|c|c|c|}
\hline \multirow{2}{*}{$\begin{array}{c}\text { TAXA DF } \\
\text { PARTICI- } \\
\text { PAÇÁ́O }\end{array}$} & \multirow[t]{2}{*}{ GRUPOS DE MUNICÍPIOS } & \multirow{2}{*}{$\begin{array}{c}\text { NÚMERO DE } \\
\text { MUNICÍPIOS } \\
\text { DE CADA } \\
\text { GRUPO }\end{array}$} & \multirow{2}{*}{$\begin{array}{c}\text { MÉDIA DAS } \\
\text { TAXAS DE } \\
\text { PARTICI- } \\
\text { PAÇÁOO }\end{array}$} & \multirow{2}{*}{$\begin{array}{l}\text { DESVIOO } \\
\text { PADRÁOO }\end{array}$} & \multicolumn{2}{|c|}{\begin{tabular}{|c|}
$\begin{array}{c}\text { INTERVALO DE } \\
\text { CONFIANÇA }(95 \%)\end{array}$ \\
LIMITES \\
\end{tabular}} \\
\hline & & & & & INFERIOR & SUPERIOR \\
\hline \multirow{6}{*}{$\begin{array}{l}\text { Mascu- } \\
\text { lina }\end{array}$} & $\begin{array}{l}\text { Grupo } 1 \text { - Municípios com } \\
\text { menor diversidade econômica, } \\
\text { localizados fora do entorno da } \\
\text { RMSP }\end{array}$ & 465 & 71,2 & 4,1 & 70,9 & 71,6 \\
\hline & $\begin{array}{l}\text { Grupo } 2 \text { - Municípios com maior } \\
\text { diversidade econômica, localiza- } \\
\text { dos fora do entorno da RMSP }\end{array}$ & 56 & 73,4 & 3,0 & 72,6 & 74,2 \\
\hline & $\begin{array}{l}\text { Grupo } 3 \text { - Municípios com maior } \\
\text { diversidade econômica, localiza- } \\
\text { dos no entorno da RMSP }\end{array}$ & 85 & 72,4 & 3,3 & 71,7 & 73,1 \\
\hline & $\begin{array}{l}\text { Grupo } 4 \text { - Municípios da RMSP } \\
\text { (independentemente da diversi- } \\
\text { dade econômica) }\end{array}$ & 39 & 71,8 & 1,9 & 71,2 & 72,4 \\
\hline & Total dos municípios & 645 & 71,6 & 3,9 & 71,3 & 71,9 \\
\hline & \multicolumn{6}{|c|}{ Teste de Brown Forsythe apresentou $p$-value $=\mathbf{0 , 0 0 0}$} \\
\hline \multirow{6}{*}{ Feminina } & $\begin{array}{l}\text { Grupo } 1 \text { - Municípios com } \\
\text { menor diversidade econômica, } \\
\text { localizados fora do entorno da } \\
\text { RMSP }\end{array}$ & 465 & 40,4 & 6,2 & 39,9 & 41,0 \\
\hline & $\begin{array}{l}\text { Grupo } 2 \text { - Municípios com maior } \\
\text { diversidade econômica, localiza- } \\
\text { dos fora do entorno da RMSP }\end{array}$ & 56 & 42,7 & 4,2 & 41,5 & 43,8 \\
\hline & $\begin{array}{l}\text { Grupo } 3 \text { - Municípios com maior } \\
\text { diversidade econômica, localiza- } \\
\text { dos no entorno da RMSP }\end{array}$ & 85 & 46,0 & 4,1 & 45,1 & 46,8 \\
\hline & $\begin{array}{l}\text { Grupo } 4 \text { - Municípios da RMSP } \\
\text { (independentemente da diversi- } \\
\text { dade econômica) }\end{array}$ & 39 & 46,8 & 3,2 & 45,8 & 47,9 \\
\hline & Total dos municípios & 645 & 41,7 & 6,1 & 41,3 & 42,2 \\
\hline & \multicolumn{6}{|c|}{ Teste de Brown Forsythe apresentou $p$-value $=0,000$} \\
\hline
\end{tabular}

FONTE DADOS ORIGINAIS DA RAIS E DO CENSO

(*) ANO BASE 2000 PARA OS DADOS DO CENSO E 2002 PARA OS DA RAIS

Com o objetivo de avançar no entendimento da relação entre a diversidade econômica e a inserção das mulheres no mercado de trabalho foi realizada regressão multinomial para medir o impacto da diversidade econômica sobre a taxa de participação feminina. Dentre as variáveis que integraram a regressão, além do número de divisóes econômicas (proxy da diversidade econômica do município), introduziu-se a variável taxa urbanização a fim aumentar o grau de precisão do cálculo, A introdução da taxa de participação foi incluída com base no pressuposto de que o grau de urbanização interfere no tamanho do Setor Terciário e, consequentemente, na diversidade da estrutura econômica. Por meio de cluster, a taxa de participaçáo feminina foi dividida em três intervalos, como indicado na tabela 7 . 
Tabela 7 Faixas de Taxa de Participação Feminina

\begin{tabular}{|l|l|}
\hline \multicolumn{1}{|c|}{ TAXA DE PARTICIPAÇÃo } & \multicolumn{1}{c|}{ INTERVALO } \\
\hline Baixa & Até 36\% \\
\hline Intermediária & Acima de 36\% até 44\% \\
\hline Alta & Acima de 44\% \\
\hline FONTE ELABORAÇÃO PRÓPRIA &
\end{tabular}

O modelo se revelou bem ajustado, com ambas variáveis (número de divisóes e taxa de urbanização) tendo efeito significativo sobre a taxa de participação feminina e boa capacidade de previsáo $(61,4 \%)$. Esse foi o percentual de acertos do modelo quando se tenta prever qual seria a categoria de taxa de participaçáo (baixa, intermediária ou alta) a que um município pertence, considerando as informaçóes referentes ao número de atividades econômicas e à taxa de urbanização.

A tabela 8 mostra os coeficientes estimados para o número de atividades econômicas e para a taxa de urbanização quando a taxa de participação feminina baixa é definida como categoria de referência. Os coeficientes indicados nessa tabela correspondem ao quociente entre a probabilidade de um município pertencer ao grupo intermediário (ou ao grupo elevado) e a probabilidade dele pertencer ao grupo de baixa taxa de participação (feminina). Em outras palavras, esses coeficientes, que são denominados de risco relativo, mostram a magnitude dos efeitos esperados sobre a taxa de participação feminina quando se altera a diversidade econômica ou o grau de urbanização dos municípios analisados. Os coeficientes exponenciados $(\operatorname{Exp}(\mathrm{B}))$ podem ser interpretados como sendo a razão entre os riscos relativos, ou seja:

- Analisando o efeito do número de atividades econômicas: com o aumento de uma atividade econômica no município, o risco relativo do grupo intermediário aumenta $8,7 \%$, enquanto que no grupo com taxa de participação feminina alta este risco relativo aumenta $16,6 \%$, mantendo-se o grau de urbanização inalterado. A partir disso é possível inferir que a expansão da diversidade econômica induz a um aumento na participação feminina;

- Analisando o efeito do grau de urbanização: a cada aumento de uma unidade no grau de urbanizaçáo, o risco relativo do grupo intermediário cresce 4,3\%, enquanto que no grupo com taxa de participação feminina alta o risco relativo aumenta 6,8\%, ceteris paribus o número de atividades econômicas. Portanto, deduz-se que o aumento na urbanização apresenta efeito similar, porém em menor magnitude, de expansão da participação feminina. 
TABEla 8 Resultados da Regressão Multinomial (a)

Municípios do Estado de Sáo Paulo, 2000/2002 (b)

\begin{tabular}{|l|c|c|}
\hline \multirow{2}{*}{ VARIÁVEIS UTILIZADAS } & \multicolumn{2}{|c|}{$\operatorname{COEFICIENTES~}(\operatorname{EXP}(\mathbf{B}))$} \\
\cline { 2 - 3 } & \multicolumn{2}{|c|}{ CATEGORIAS DE PARTICIPAÇÃo FEMININA } \\
\cline { 2 - 3 } & INTERMEDIÁRIA & ELEVADA \\
\hline Número de Atividades Econômicas & 1,087 & 1,166 \\
\hline Taxa de Urbanização & 1,043 & 1,068 \\
\hline
\end{tabular}

FONTE DADOS ORIGINAIS DA RAIS E DO CENSO

(A) A CATEGORIA DE REFERÊNCIA É A TAXA DE PARTICIPAÇÃO FEMININA BAIXA

(B) ANO BASE 2000 PARA OS DADOS DO CENSO E 2002 PARA OS DA RAIS

Os resultados da pesquisa ganham relevância quando reforçam a idéia de que presença de baixas taxas de desemprego podem não necessariamente estar associadas a movimentos favoráveis da economia e do mercado de trabalho. Explicando melhor: em algumas regióes ou localidades, a taxa de desemprego pode estar subdimensionada porque parte dos desempregos estaria escondida à sombra da inatividade. A tabela 9 mostra que a taxa de desemprego total do Grupo 4 (21,5\%) é quase duas vezes maior que a taxa de desemprego do Grupo $1(12,4 \%)$.

No entanto, a tabela 9 também mostra que as áreas com menor taxa de desemprego são exatamente aquelas que apresentam as menores taxas de participação. Portanto, náo se pode descartar a possibilidade de que o aumento do crescimento econômico nos municípios especializados localizados no interior do Brasil estimule a entrada de mulheres no mercado de trabalho, eliminando a aparente situação positiva sugerida pela baixa taxa de desemprego nesses espaços. Em outras palavras, a observaçáo de baixos níveis de desemprego no interior do Brasil, sobretudo nas pequenas cidades, não deveria ser interpretado como um sinal de um mercado de trabalho vigoroso e favorável. É preciso avançar em políticas públicas que sejam desenhadas de acordo com as necessidades particulares dos territórios.

TABela 9 | Taxas de Participaçáo e de Desemprego segundo diversidade econômica. Municípios do Estado de São Paulo - 2000/2002 $\left(^{*}\right)$

\begin{tabular}{|l|c|c|c|c|c|}
\hline \multicolumn{1}{|c|}{ AGRUPAMENTOS DE MUNICÍPIOS } & $\begin{array}{c}\text { MÉDIA DE } \\
\text { DIVISÓES } \\
\text { ECONÔMICAS }\end{array}$ & $\begin{array}{c}\text { TAXAS DE } \\
\text { PARTICIPAÇÃo } \\
\text { (MÉDIAS) }\end{array}$ & \multicolumn{2}{|c|}{$\begin{array}{r}\text { TAXAS DE } \\
\text { DESEMPREGO } \\
\text { (MÉDIAS) }\end{array}$} \\
\cline { 4 - 6 } & TOTAL & FEMININA & TOTAL & FEMININA \\
\hline $\begin{array}{l}\text { Grupo 4 - Municípios da RMSP (indepen- } \\
\text { dentemente da diversidade econômica) }\end{array}$ & 43 & 59,2 & 46,8 & 21,5 & 27,8 \\
\hline $\begin{array}{l}\text { Grupo 3 - Municípios com maior diver- } \\
\text { sidade econômica, localizados no entorno } \\
\text { da RMSP }\end{array}$ & 37 & 59,3 & 46,0 & 15,8 & 21,8 \\
\hline $\begin{array}{l}\text { Grupo 2 - Municípios com maior diver- } \\
\text { sidade econômica, localizados fora do } \\
\text { entorno da RMSP }\end{array}$ & 24 & 58,2 & 42,7 & 13,1 & 20,0 \\
\hline $\begin{array}{l}\text { Grupo 1 - Municípios com menor } \\
\text { diversidade econômica, localizados fora do } \\
\text { entorno da RMsP }\end{array}$ & 22 & 56,1 & 40,4 & 12,4 & 18,7 \\
\hline
\end{tabular}

FONTE RAIS E CENSO

$(*)$ ANO BASE 2000 PARA OS DADOS DO CENSO E 2002 PARA OS DA RAIS 


\section{Consideraçóes finais}

Os resultados obtidos nesse artigo sobre o mercado de trabalho nos municípios do Estado de São Paulo apontam para algumas mediaçóes que podem contribuir para o avanço do papel exercido pelo espaço e, particularmente da distribuiçáo das atividades produtivas, sobre o comportamento da taxa de desemprego. Naturalmente, os fenômenos observados em Sáo Paulo não podem ser diretamente transpostos para outros estados e regióes brasileiras, tendo em vista o elevado nível de renda e de complexidade das cadeias produtivas localizadas em São Paulo em comparação com a média dos municípios brasileiros. De fato, alguns municípios do interior do país contam com elevada especialização na produção de commodities para exportação e frágeis relaçôes econômicas com as áreas no entorno. Diante de tais circunstâncias, espera-se que os efeitos negativos da especializaçáo econômica sobre o mercado de trabalho possam ser ainda maiores. Enfim, a investigação realizada em São Paulo talvez possa servir de ponto de partida para estudos com maior amplitude nos diferentes quadrantes do território nacional.

Embora seja preciso avançar na discussão sobre a relação entre desemprego e espaço, os resultados obtidos nesse trabalho não deixam dúvidas sobre a necessidade de avançar na discussão de modelos de políticas de emprego e de desenvolvimento regional. No Brasil e em várias partes do mundo, o cerne das políticas regionais e desenvolvimento local está muitas vezes orientado para atração de investimentos privados por meio do oferecimento de benefícios fiscais. Existem situaçóes nas quais indústrias capital-intensivas, que geram baixo impacto na taxa desemprego e no desenvolvimento das cadeias produtivas locais, contam com generosos incentivos governamentais. Portanto, a reflexão dos impactos da especialização econômica sobre o mercado de trabalho pode contribuir para o aprimoramento das políticas de desenvolvimento local.

O debate sobre a especialização econômica e mercado de trabalho também pode ser útil para o aprimoramento das políticas de geração de emprego. A corrente dominante da literatura econômica estabeleceu que a formação educacional/profissional, i.e., o capital humano, estaria entre as principais razóes que explicam o êxito dos indivíduos no mercado de trabalho. De fato, estatísticas de diferentes países mostram que a taxa de desemprego tende a ser menos elevada entre os indivíduos com maior escolaridade. A partir da teoria do capital humano e dos conceitos de competiçáo e eficiência que sustentam os modelos da corrente dominante, muitos países passaram a desenhar suas políticas de geração de emprego baseados quase exclusivamente em programas de treinamento e qualificação profissional. No entanto, a ênfase da qualificação profissional como estratégia para o combate ao desemprego tende a deslocar o problema do lado da demanda para o da oferta. Em outras palavras, a existência de situaçóes de desemprego seria explicada pela ausência de qualificação do indivíduo (lado da oferta) e não pelas insuficiência do mercado (lado da demanda). Enfim, a adesão da tese do capital humano coloca o governo numa posição bastante confortável, pois o desemprego não seria resultado de políticas econômicas equivocadas, mas da insuficiente qualificação dos trabalhadores. 
Portanto, a discussão levada a cabo nesse artigo sobre as relaçóes entre a especialização produtiva e o emprego pode contribuir para o debate sobre o desenho das políticas de geração de emprego. $\mathrm{Na}$ ausência de novas oportunidades de trabalho, o investimento em capital humano apenas acirra a competição e a desigualdade no mercado de trabalho, enquanto seus efeitos sobre o desemprego são praticamente nulos. Em casos extremos, a ênfase na qualificação pode levar a situaçóes de sobre-educação (over-education), nas quais os indivíduos contam com habilidades e formação educacional superiores às necessidades das funçóes que desempenham em seu posto de trabalho. Oliveira e Abrantes Filho (2011) mostraram que a sobre-educação é um fenômeno bastante conhecido na Europa e que já pode ser encontrado no Brasil em algumas categorias profissionais específicas

Enfim, longe de considerar os resultados obtidos nesse trabalho como o final de um percurso de pesquisa, eles devem ser entendidos como um ponto de partida para a definição de novas agendas de pesquisa e, sobretudo, para a reflexão de novas estratégias de atuação governamental que sejam capazes de romper com o conforto e a segurança dos modelos baseados na corrente econômica dominante.

\section{Referências bibliográficas}

Cohen, M., Lerman, R. I. \& Rea Jr., S. A. (1971). Area employment conditions and laborforce participation: A microstudy. The Journal of Political Economy, 79(5), 1151-1160. http://dx.doi.org/10.1086/259824

Dedecca, C. S. (2005). Notas sobre a evolução do mercado de trabalho no Brasil. Revista de Economia politica, 25, 1 (97), 94-111. http://www.rep.org.br/pdf/97-6.pdf

Gonzaga, G. \& Reis, M. (2005). Os efeitos trabalhador adicional e desalento no Brasil. Anais do XXXIII Encontro Nacional de Economia, Natal (Rio Grande do Norte), 6 a 9 de dezembro 2005. [Publicaçáo oficial: Oferta de trabalho e ciclo econômico: Os efeitos trabalhador adicional e desalento no Brasil, Revista Brasileira de Economia 65(2), 127-148 (Feb. 2005), doi: 10.1590/S0034-71402011000200002]

Harris, J. H. \& Todaro, M. P. (1980). Migração, desemprego e desenvolvimento: uma análise com dois setores. In H. A. Moura (Coord.), Migração interna: Textos selecionados (pp. 173-209). Fortaleza: Banco do Nordeste do Brasil (вNB).

Kain, J. F. (1968). Housing segregation, negro employment, and metropolitan decentralization. The Quarterly Journal of Economics, 82(2), 175-197. doi: 10.2307/1883085

Keynes, J. M. (1983) Teoria Geral do Emprego, do Juro e do Dinheiro. São Paulo: Ed. Abril.

Lee, E. S. (1980), Uma teoria sobre a migração. In: H. A Moura (Coord.), Migração interna: Textos selecionados (pp. 89-114). Fortaleza: Banco do Nordeste do Brasil (BNB).

Leone, E. T. (1999). Renda familiar e trabalho da mulher na Região Metropolitana de São Paulo nos anos 80 e 90. Texto para discussäo 81, Campinas, Instituto de Economia, Universidade Estadual de Campinas (IE/UniCAMP). http://www.abep.nepo.unicamp. br/docs/outraspub/trabalhogenero/TG_p85a110.pdf 
Lima, R. (1980). Mercado de trabalho: o capital humano e a teoria da segmentação. Pesquisa e Planejamento Econômico, 10(1), 217-272. http://ppe.ipea.gov.br/index.php/ppe/ article/viewFile/497/439

Mooney, J. D. (1967). Urban poverty and labor force participation. American Economic Review, 57(1), 104-119.

Oliveira, A. (2006). Território e Mercado de Trabalho: discursos \& teorias. São Paulo: Edunesp.

Oliveira, A. \& Abrantes Filho, G. (2011). Education and labor market in Brazil. Policy futures in education, 9(5), 585-597. doi: 10.2304/pfie.2011.9.5.585

Oliveira, L. \& Carvalho, H. (2008). A precarização do emprego na Europa. Revista de Ciências Sociais (DADOS), 51(3), 541-567. http://dx.doi.org/10.1590/S001152582008000300001

Ranis, G. \& Fei, J. C. H. (1964). Development of the labor surplus economy: Theory and policy. Homewood, IL: Richard D. Irwin, Inc.

Ravenstein, E. G. (1980). As leis da migração. In H. A. Moura (Coord.), Migração interna: Textos selecionados (pp. 19-88). Fortaleza: Banco do Nordeste do Brasil (BNB).

Reich, M., Gordon, D. M. \& Edwards, R. C. (1973). Dual labor markets: A theory of labor market segmentation. The American Economic Review, 63(2), Papers and Proceedings of the Eighty-fifth Annual Meeting of the American Economic Association, 359-365. 